\title{
Educação ambiental: $O$ trabalho desenvolvido por professores de uma escola pública do interior da Paraíba
}

\author{
Environmental education: The work of teachers of a public school in the interior of Paraíba
}

\author{
SANTOS $^{1}$, J. O. dos; SANTOS ${ }^{2}$, R. M. S.; SANTOS SEGUNDO ${ }^{3}$, J. O.; SANTOS V. C. ${ }^{4}$ \\ joseozildo2014@outlook.com
}

\section{Resumo}

Diante dos problemas ambientais que se avolumam, a necessidade da construção de uma consciência ecológica coletiva é algo por demais patente. E, esse processo deve ter na escola o seu principal sustentáculo. Através da Educação Ambiental, o professor pode explorar vários temas, a exemplo de meio ambiente, desenvolvimento sustentável, responsabilidade socioambiental, além da ética ambiental, que, de certa forma, encontram-se correlacionados. O presente artigo tem por objetivo mostrar como os professores de uma escola pública do município de Patos, Paraíba, vêm trabalhando a Educação Ambiental em sala de aula. Uma significativa conclusão proporcionada por esta pesquisa diz respeito ao fato de que a escola a qual se encontram vinculados os entrevistados, precisa dar uma maior visibilidade às suas ações, de forma que todos os docentes tenham o conhecimento pleno quanto ao desenvolvimento dos projetos ambientais e deles participem, adquirindo uma melhor percepção ambiental e assim possam contribuir para transformar sua unidade educativa em uma escola promotora da sustentabilidade.

Palavras-chave: Educação Ambiental; Prática Pedagógica; Avaliação.

\begin{abstract}
In the face of environmental problems looming, the need for construction of a collective ecological awareness is something too patent. And this process must have at school your mainstay. Through environmental education, the teacher can explore several issues, like the environment, sustainable development, environmental responsibility, as well as environmental ethics, which, in a way, are correlated. This article aims to show how the teachers of a public school in Patos county, Paraíba, have been working on environmental education in the classroom. A significant conclusion provided by this research is the fact that the school to which they are bound to respondents, need to give greater visibility to their actions, so that all teachers have the knowledge about the development of environmental projects and their participate, acquiring a better environmental awareness and thus can contribute to transform its educational unit in a school promoting sustainability.
\end{abstract}

Keywords: Environmental Education; Teaching Practice; Evaluation.

\section{INTRODUÇÃO}

Nos últimos anos, a Educação Ambiental conquistou um significativo espaço no contexto escolar, sendo, principalmente, abordada como tema transversal, na forma definidas pelas resoluções da Rio-92. Contudo, apesar do empenho dos professores na ampliação das discussões sobre as questões ambientais em sala de aula, ainda existe muito a ser feito para que o educando

${ }^{1}$ José Ozildo dos Santos, Centro de Desenvolvimento Sustentável do Semiárido, Universidade Federal de Campina Grande, Sumé $P B$, Brasil.

${ }^{2}$ Rosélia Maria de Sousa Santos, Programa de Pós-Graduação Stricto Sensu em Sistemas Agroindustriais - PPGSA, Universidade Federal de Campina Grande, Pombal-PB, Brasil.

${ }^{3} J o s e ́$ Ozildo dos Santos Segundo, Centro de Educação (CE), Departamento de Fundamentos e Políticas da Educação (DFPE), Universidade Federal do Rio Grande do Norte (UFRN), Natal-RN, Brasil.

${ }^{4}$ Vanessa da Costa Santos, Programa de Pós-Graduação Stricto Sensu em Sistemas Agroindustriais - PPGSA, Universidade Federal de Campina Grande, Pombal-PB, Brasil. 
realmente passe a ter uma consciência quanto à gravidade dos problemas ambientais (BUARQUE, 2013).

Na realidade, a sociedade como um todo ainda não acordou para esse problema. E, muitas vezes, a falta de compromisso por parte dos gestores públicos quanto à promoção da Educação Ambiental (EA), constitui-se no principal obstáculo ao seu desenvolvimento dentro e fora da escola.

Esclarecem Stadler e Maioli (2012), que diante dos problemas ambientais que se avolumam, a necessidade da construção de uma consciência ecológica coletiva é algo por demais patente. E, esse processo deve ter na escola o seu principal sustentáculo.

Diante disto, cabe ao professor a responsabilidade de desenvolver um processo educativo que possibilite a mudança de mentalidade do educando, tornando-o consciente de seu papel na luta pela preservação da natureza e pela valorização da biodiversidade.

Pois, segundo Santos et al (2013, p. 29):

As soluções para os problemas ambientais somente serão possíveis se houver envolvimento e participação de toda a sociedade juntamente com o apoio de políticas públicas condizentes, pois tais problemas não podem ser resolvidos individualmente, nem por movimentos isolados das comunidades.

Através da Educação Ambiental, o professor pode explorar vários temas, a exemplo de meio ambiente, desenvolvimento sustentável, responsabilidade socioambiental, além da ética ambiental, que, de certa forma, encontram-se correlacionados. Levando em consideração o que acima foi exposto, o presente artigo tem por objetivo mostrar como os professores de uma escola pública do município de Patos, Paraíba, vêm trabalhando a Educação Ambiental em sala de aula.

\section{METODOLOGIA}

Trata-se de uma pesquisa exploratória e de natureza qualitativa, realizada junto aos professores da Escola Estadual de Ensino Médio e Fundamental 'José Alves Gomes, localizada no município de Patos, Estado da Paraíba, possuindo 430 alunos, matriculados em nove turmas do ensino fundamental e oito do ensino médio. De acordo com Gil (2002, p. 34):

A pesquisa exploratória é usada quando se busca um entendimento sobre a natureza geral de um problema, as possíveis hipóteses alternativas e as variáveis relevantes que precisam ser consideradas. Normalmente, existe pouco conhecimento prévio daquilo que se pretende conseguir. Os métodos são muito flexíveis, não estruturados e qualitativos, para que o pesquisador comece seu estudo sem pré-concepções sobre aquilo que será encontrado. 
Esse tipo de pesquisa tem por objetivo oportunizar ao pesquisador de um maior conhecimento sobre o tema ou problema em estudo. Por isso, é utilizado quando se tem noção muito vaga do problema da pesquisa.

O universo da presente pesquisa foi composto por vinte e cinco professores, do qual se retirou uma amostra composta por dez participantes, escolhidos de forma aleatória, dentre aqueles que demonstraram interesse em participar deste estudo. Para a coleta de dados utilizou-se um questionário previamente elaborado, composto por questões subjetivas, relacionadas aos objetivos estabelecidos para esta pesquisa. Os dados colhidos foram apresentados em gráficos, para posterior discussão à luz da literatura especializada.

\section{RESULTADOS E DISCUSSÃO}

Inicialmente, procurou-se saber dos professores entrevistados sobre a Educação Ambiental. Os dados obtidos com esse questionamento encontram-se apresentados na Figura abaixo.

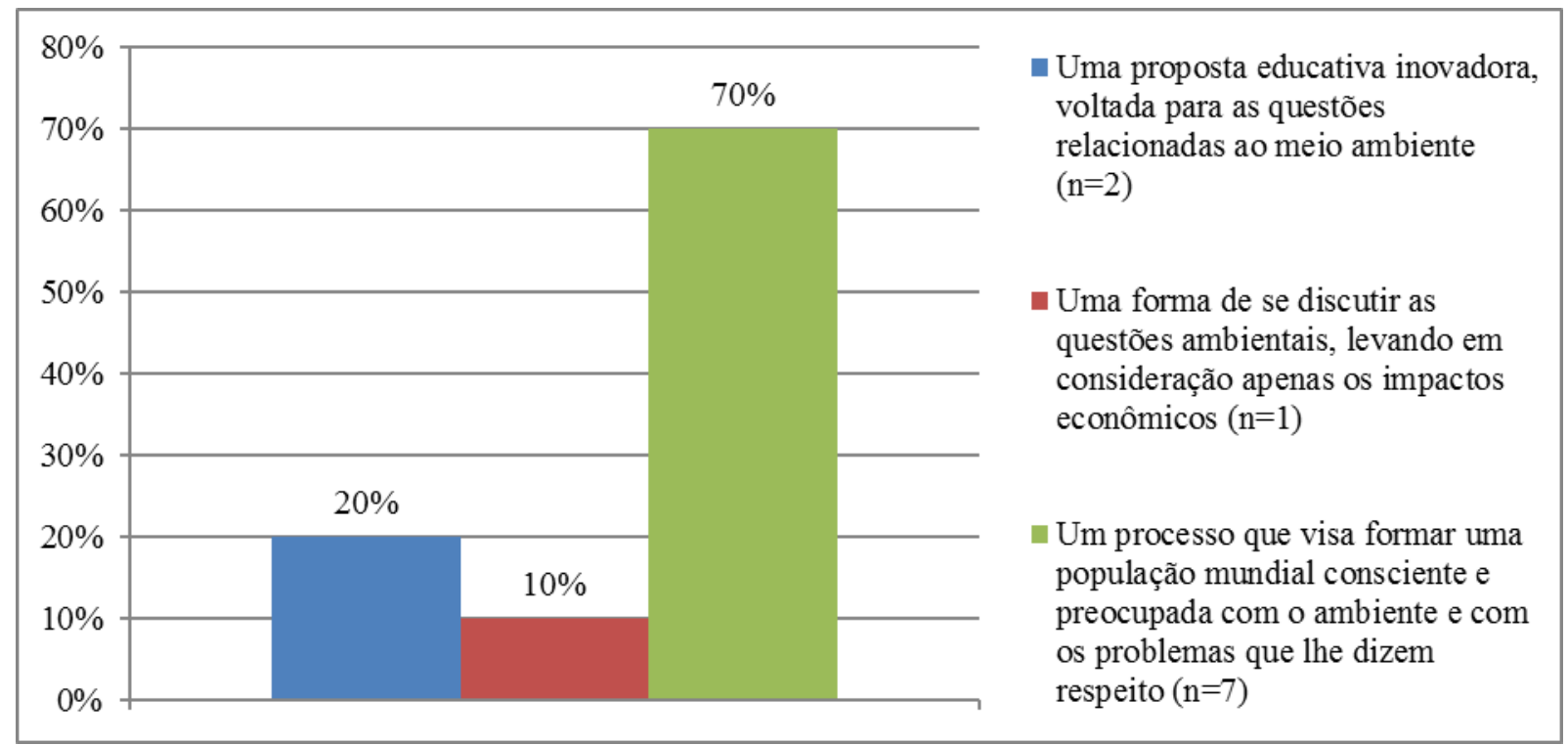

Figura 01. Gráfico com a distribuição dos participantes quanto ao que é educação ambiental

Fonte: Elaborado pelos autores

Analisando-se a Figura 01 verifica-se que de acordo com 20\% dos professores entrevistados, a Educação Ambienta é vista como sendo uma proposta educativa inovadora, voltada para as questões relacionadas ao meio ambiente, $10 \%$ entendem tal disciplina como sendo uma forma de se discutir as questões ambientais, levando em consideração apenas os impactos econômicos. No entanto, $70 \%$ definem a Educação Ambiental como sendo um processo que visa 
formar uma população mundial consciente e preocupada com o ambiente e com os problemas que lhe dizem respeito, seguindo praticamente o conceito apresentado pela UNESCO.

Embora existam várias definições para a Educação Ambiental, utiliza-se com uma maior frequência a definição apresentada durante o Congresso de Belgrado, promovido pela UNESCO em 1975, oportunidade em que a EA foi definida como sendo um processo que visa "formar uma população mundial consciente e preocupada com o ambiente e com os problemas que lhe dizem respeito", capaz de "trabalhar individualmente e coletivamente para resolver os problemas atuais e impedir que se repitam" (UNESCO apud MARCATTO, 2002, p. 14).

Deve-se registrar que a EA é um processo que objetiva promover a conscientização coletiva da sociedade em relação à necessidade de preservar o meio ambiente como um todo, formando cidadãos conscientes quanto ao seu papel nesse processo de preservação (DIAS, 2003).

Destaca Marcatto (2002, p. 12) que "a educação ambiental é uma das ferramentas existentes para a sensibilização e capacitação da população em geral sobre os problemas ambientais", servindo como instrumento facilitador da "tomada de consciência sobre a gravidade dos problemas ambientais".

Assim, pelo demonstrado, a EA é um processo que busca mudar a forma de como o ser humano ver o meio ambiente, envolvendo-o nas discussões sobre os problemas ambientais, tornando-o responsável pela construção de um mundo no qual se garanta condições dignas de vida para as gerações futuras, de forma que estas possam desfrutar também dos recursos naturais hoje existentes.

Num segundo momento, procurou-se saber dos professores que participaram da presente pesquisa o que vem a ser meio ambiente. As respostas colhidas nesse questionamento foram transformadas em dados e apresentadas na Figura 02. 


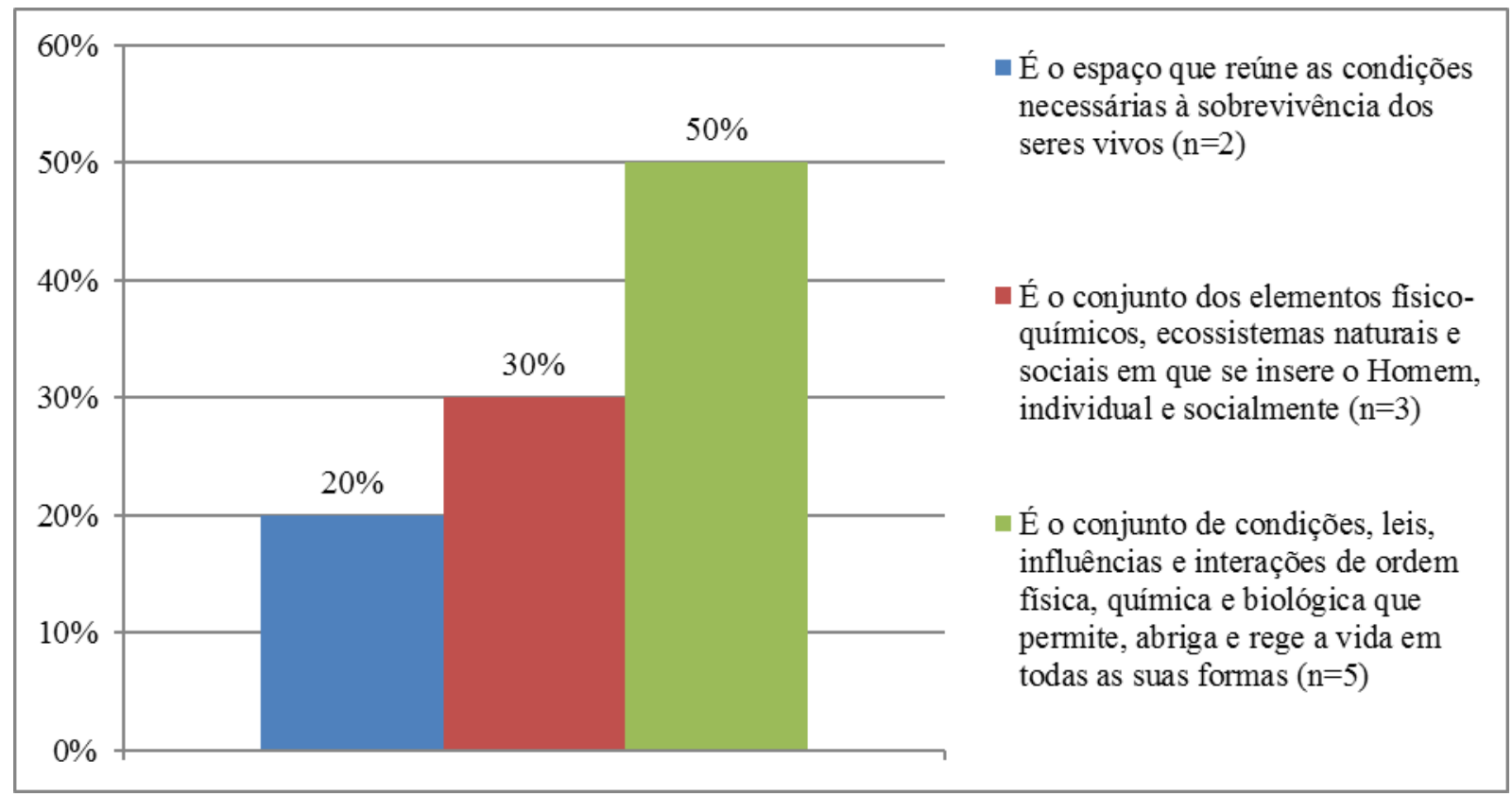

Figura 02. Gráfico com a distribuição dos participantes quanto ao que vem a ser Meio Ambiente

Fonte: Elaborado pelos autores

Com base nos dados apresentados na Figura 02, para 20\% dos professores entrevistados, meio ambiente é o espaço que reúne as condições necessárias à sobrevivência dos seres vivos; $30 \%$ entendem como sendo o conjunto dos elementos físico-químicos, ecossistemas naturais e sociais em que se insere o homem, individual e socialmente. Contudo, $50 \%$ definem o termo meio ambiente como sendo o conjunto de condições, leis, influências e interações de ordem física, química e biológica que permite, abriga e rege a vida em todas as suas formas.

O próprio IBGE (2004, p. 210) define meio ambiente como sendo o "conjunto dos agentes físicos, químicos, biológicos e dos fatores sociais susceptíveis de exercerem um efeito direto ou mesmo indireto, imediato ou a longo prazo, sobre todos os seres vivos, inclusive o homem".

Vários são os conceitos existentes para o termo 'meio ambiente'. No entanto, a noção básica que se tem sobre o mesmo é a de que trata-se de tudo que existe em volta dos seres vivos, incluindo também aquilo que não possui vida, além das manifestações socioculturais. Assim, o meio ambiente diz respeito aos fatores bióticos, edáficos e climáticos que determinam a sobrevivência dos seres vivos sobre a Terra (JACOBI, 2003).

Posteriormente, procurou-se saber dos professores entrevistados, se na escola onde trabalham existe ou não algum projeto de Educação Ambiental. Os resultados colhidos foram esboçados na Figura 03. 


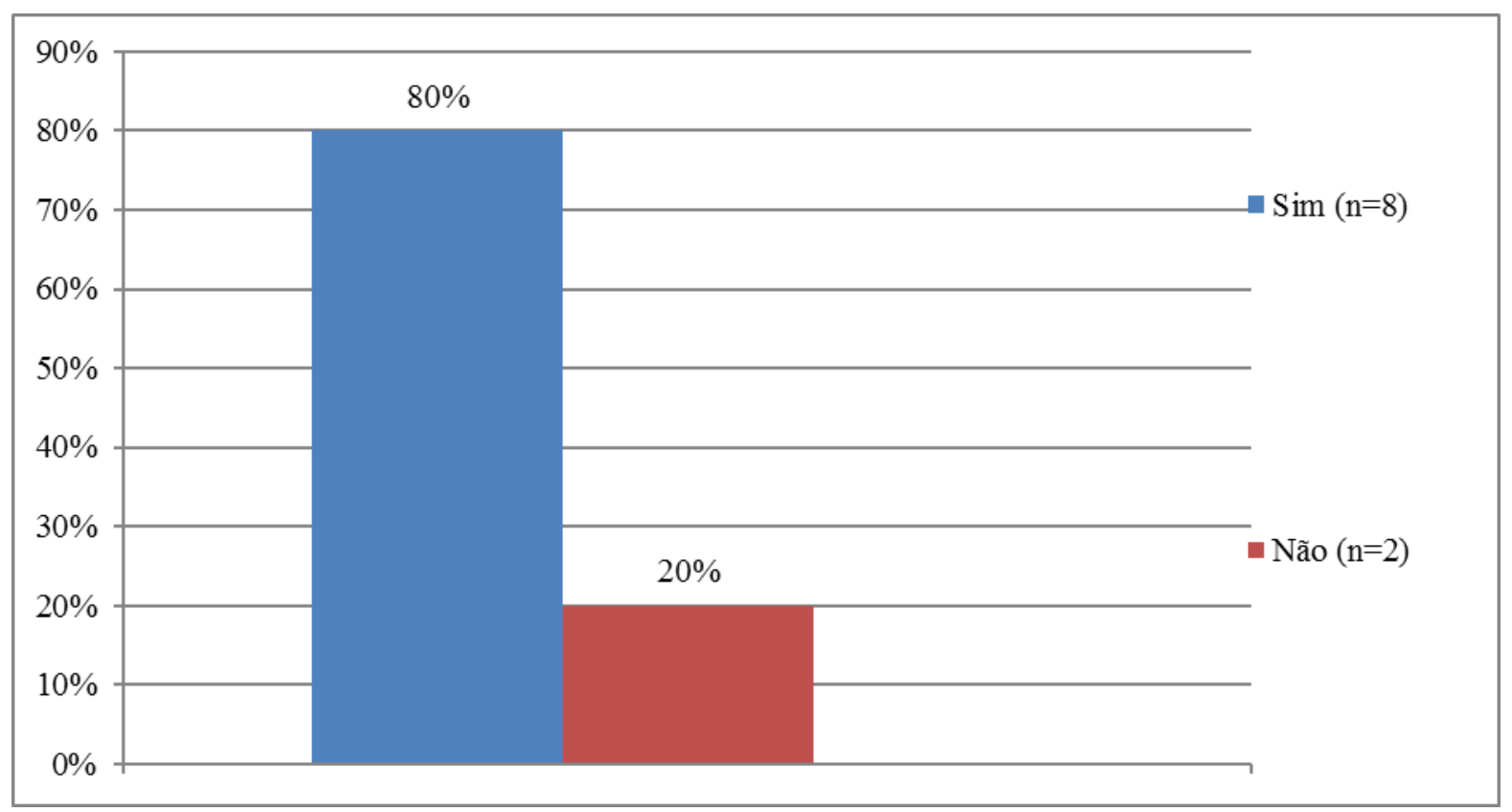

Figura 3. Gráfico com a distribuição dos participantes quanto à existência ou não de algum projeto de Educação Ambiental em sua escola. Fonte: Elaborado pelos autores

Quando se analisa a Figura 03 verifica-se que segundo 80\% dos professores entrevistados, na escola onde trabalham existe um projeto de Educação Ambiental sendo desenvolvido. Entretanto, 20\% afirmaram que não vendo sendo desenvolvido nenhum projeto nesse sentido. Os dados colhidos demonstram que a escola e os professores que trabalham a questão ambiental precisam dar uma maior visibilidade às suas ações.

De acordo com Medeiros et al. (2011, p. 1), as escolas “já estão conscientes que precisam trabalhar a problemática ambiental e muitas iniciativas tem sido desenvolvida em torno desta questão, incorporando a temática do meio ambiente nos sistemas de ensino como tema transversal dos currículos escolares".

Desta forma, levando em consideração a importância que a educação ambiental desfruta na atualidade, são poucas as escolas que não desenvolvem um projeto envolvendo a temática meio ambiental, relacionado à reciclagem, às hortas escolares, à arborização, etc. (SILVA; TAVARES, 2009).

Com tais projetos, a escola objetiva conscientizar seus alunos sobre a importância da necessidade de se preservar o meio ambiente. Assim, com essas iniciativas vem se ampliando o chamado conceito de 'escolas sustentáveis', que são aquelas unidades educativas voltadas para a promoção da educação para a vida, levando em consideração o meio onde o aluno vive e as condições de sustentabilidades. 
Posteriormente, indagou-se dos professores participantes, de que forma eles trabalham a temática ambiental em suas disciplinas. A Figura 04 sintetizam os dados relativos a esse questionamento.

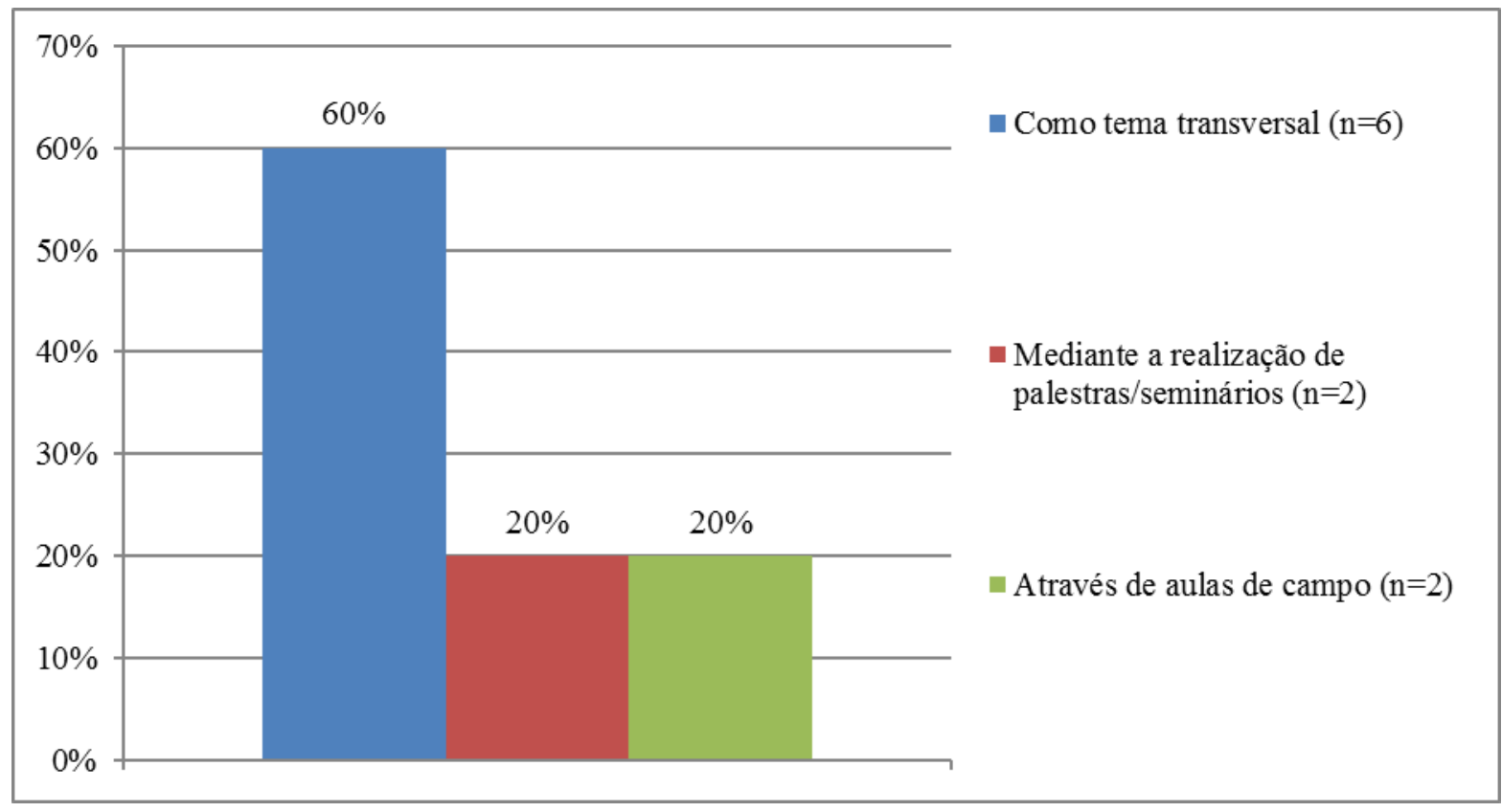

Figura 04: Gráfico com a distribuição dos participantes quanto à forma como trabalham a temática ambiental em suas disciplinas. Fonte: Elaborados pelos autores

Quando se analisa a Figura 04, verifica-se que 60\% dos professores entrevistados trabalham a temática ambiental como um tema transversal; 20\% declararam que exploram a referida temática mediante a realização de palestras ou seminários e outros $20 \%$ informaram que utilizam-se de aulas de campo para trabalharem a temática meio ambiente.

De acordo com Sato (2002, p. 37), "há diferentes formas de incluir a temática ambiental nos currículos escolares, como atividades artísticas, experiências práticas, atividades fora de sala de aula, produção de materiais locais e projetos [...]", cabendo aos docentes, "por intermédio de prática interdisciplinar, proporem novas metodologias que favoreçam a implementação da Educação Ambiental".

Diante da necessidade de se trabalhar a Educação Ambiental, cabe à escola a missão de procurar a melhor maneira, objetivando tornar possível uma aprendizagem significativa. Assim, em toda e qualquer ação desenvolvida, a escola deve proporcionar a participação de todos os seus alunos, revendo, se necessário, o currículo de forma a garantir um melhor desenvolvimento da interdisciplinaridade. 
De acordo com Marcatto (op. cit., p. 19), no contexto escolar atual "propõe-se que as questões ambientais não sejam tratadas como uma disciplina específica, mas sim que permeiem os conteúdos, objetivos e orientações didáticas em todas as disciplinas".

Independente da disciplina que leciona, o professor em sua sala de aula deve abordar o meio ambiente e os questionamentos a ela relacionados, seja como parte dos conteúdos didáticos ou em forma de tema transversal.

Nesse sentido, expressam os Parâmetros Curriculares Nacionais (BRASIL, 1997, p. 64), que a transversalidade "pressupõe um tratamento integrado das áreas e um compromisso das relações interpessoais e sociais escolares com as questões que estão envolvidas nos temas", proporcionando "uma coerência entre os valores experimentados na vivência que a escola propicia aos alunos e o contato intelectual com tais valores".

Analisando a citação transcrita acima, percebe-se que a transversalidade é um recurso que em muito enriquece a aula. Através de tal recurso, é possível o professor de Matemática, por exemplo, abordar em sala de aula as questões ambientais, discutindo, em termos percentuais, quanto do território brasileiro vem sofrendo com a degradação ambiental, transformando tal fenômeno em números, exprimindo-o em percentuais.

Ao utilizar tal recurso o professor consegue melhor contextualizar suas aulas, fazendo com que as mesmas sejam facilmente compreendidas por seus alunos. Em síntese, através dos temas transversais pode-se promover um melhor debate no contexto da sala de aula, fazendo com que o aluno interaja por completo com o conteúdo que está sendo apresentado, fator determinante para produção de uma aprendizagem significativa (ALMEIDA, 2007).

Através do quinto questionamento, perguntou-se aos professores participantes se eles acham difícil trabalharem a educação ambiental no contexto de suas disciplinas. As respostas oferecidas foram transformadas em dados e apresentadas na Figura 05. 


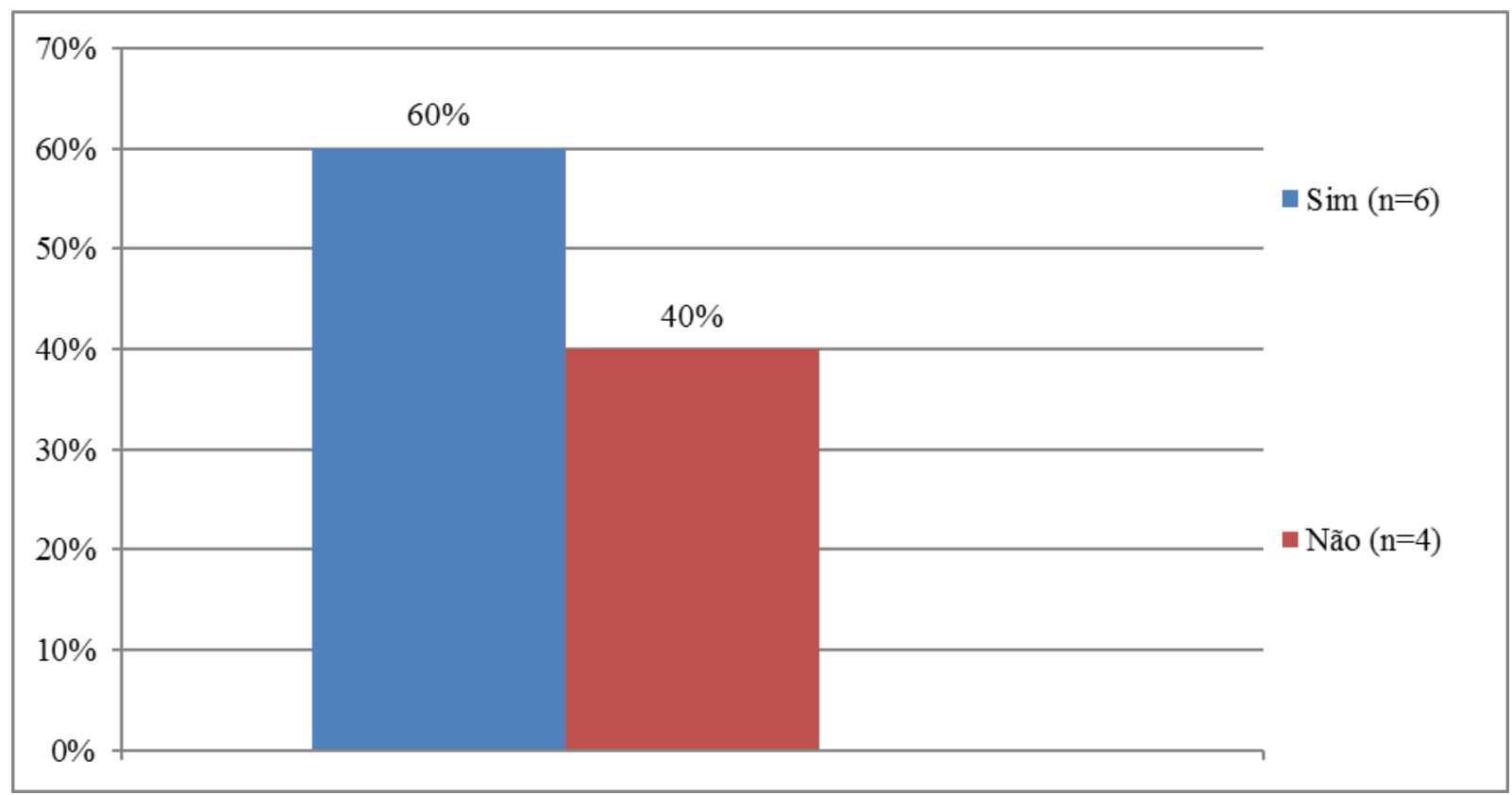

Figura 05. Gráfico com a distribuição dos participantes quanto ao fato se acham ou não difícil trabalharem a educação ambiental no contexto de sua disciplina. Fonte: Elaborado pelos autores

Analisando os dados apresentados na Figura 5 verifica-se que $60 \%$ dos professores entrevistados acham difícil trabalharem a temática ambiental em suas disciplinas. No entanto, $40 \%$ afirmaram que não enfrentam nenhuma dificuldade.

Segundo Medeiros et al. (op. cit, p. 8) "para muitos professores trabalhar temas transversais como o meio ambiente no cotidiano escolar é muito difícil, pois as salas de aula são sempre lotadas, com muitos conteúdos para serem lecionados durante o ano letivo, o qual deve ser cumprido segundo a grade curricular".

Apesar de ser um tema bastante atual explorado com muita frequência não somente pela escola como também pela mídia, as questões ambientais ainda se apresentam como complexas, exigindo uma releitura constante, diante dos diferentes posicionamentos que envolvem à ética e a sustentabilidade. No entanto, tem-se que reconhecer que grande parte das dificuldades enfrentadas pelos professores em sala de aula, quanto à educação ambiental, são resultantes de uma formação acadêmica incompleta.

\section{CONSIDERAÇÕES FINAIS}

Esta pesquisa possibilitou concluir que a maioria dos professores entrevistados entende a Educação Ambiental como um processo que tem por objetivo construir uma sociedade consciente sobre a necessidade de se preservar o meio e de se discutir as questões a ele relacionadas. E, que o 
meio ambiente é um conjunto de condições, que permitem a existência dos seres vivos na Terra. E, que por essa razão, deve ser preservado.

Uma significativa conclusão proporcionada por esta pesquisa diz respeito ao fato de que a escola a qual se encontram vinculados os entrevistados, precisa dar uma maior visibilidade às suas ações, de forma que todos os docentes tenham o conhecimento pleno quanto ao desenvolvimento dos projetos ambientais e deles participem, adquirindo uma melhor percepção ambiental e assim possam contribuir para transformar sua unidade educativa em uma escola promotora da sustentabilidade.

Os dados coletados também demonstraram que todos os professores entrevistados, independentemente da disciplina que lecionam, trabalham a temática ambiental em suas salas de aulas, e, que a maioria faz isto de forma transversal, embora considere difícil trabalhar tal temática.

\section{REFERÊNCIAS}

ALMEIDA, G. P. Transposição didática: por onde começar. São Paulo: Cortez, 2007, 248p.

BRASIL. Secretaria de Educação Fundamental. Parâmetros curriculares nacionais: primeiro e segundo ciclos do ensino fundamental (Tema Transversal Saúde). Secretaria de Educação Fundamental - Brasília: MEC/SEF, 1997, 286p.

DIAS, G. F. Um grande desafio: dimensões humanas das alterações globais. In: DIAS, G. F. (org.). Educação ambiental: princípios e práticas. São Paulo: Gaia, 2003, 198p.

IBGE - Instituto Brasileiro de Geografia e Estatística. Vocabulário básico de recursos naturais e meio ambiente. 2 ed. Rio de Janeiro: IBGE, 2004, 504p.

GIL, A. C. Como elaborar projetos de pesquisa. 10 ed. São Paulo: Atlas, 2002.

JACOBI, P. Educação Ambiental, cidadania e sustentabilidade. Cadernos de pesquisa, n. 118, março, 2003.

MARCATTO, C. Educação ambiental: conceitos e princípios. Belo Horizonte: FEAM, 2002, $264 p$. 
MEDEIROS, A. B. et al. A Importância da educação ambiental na escola nas séries iniciais. Revista Faculdade Montes Belos, v. 4, n. 1, p. 1-17, set., 2011.

MELO, S. S. de; TRAJBER, R. Vamos cuidar do Brasil: conceitos e práticas em educação ambiental na escola. Brasília: Ministério da Educação, Coordenação Geral de Educação Ambiental: Ministério do Meio Ambiente, Departamento de Educação Ambiental: UNESCO, 2007, 432p.

SANTOS, R. M. S. [et al]. A necessidade de uma nova conscientização ambiental: A educação ambiental como prática. Revista Brasileira de Educação e Saúde, v. 3, n. 2, p. 28-33 abr.-jun., 2013.

SATO, M. Educação ambiental. São Carlos-SP: Rima, 2002, 334p.

SILVA, C. C. M. B.; TAVARES, H. M. Educação ambiental e cidadania. Revista da Católica, Uberlândia, v. 1, n. 2, p. 149-158, 2009.

Recebido em: 14/08/2016

Aceito para publicação em: 01/10/2016 